\title{
Development of a New Tapping Tool Covered with Nickel/Abrasive Particles Composite Film for Preventing Chip Snarling and Tool Service Life Extension
}

\author{
Yasuyoshi Saito ${ }^{1)^{*}}$, Takeshi Yamaguchi ${ }^{1)}$, Kei Shibata ${ }^{1)}$, Yuki Kadota ${ }^{1)}$, Takeshi Kubo ${ }^{2)}$, \\ Wataru Watanabe ${ }^{2}$ and Kazuo Hokkirigawa ${ }^{1)}$ \\ ${ }^{1)}$ Graduate School of Engineering, Tohoku University \\ 6-6-01 Aramaki Aza-Aoba, Aoba-ku, Sendai, Miyagi 980-8579, Japan \\ ${ }^{2)}$ MIYAGITANOI MFG. CO., LTD \\ 15-1 Shichigashuku-machi Aza-Hagisaki, Katta-gun, Miyagi 989-0537, Japan \\ *Corresponding author: saito@gdl.mech.tohoku.ac.jp
}

( Manuscript received 25 August 2015; accepted 07 December 2015; published 30 April 2016 )

( Presented at the International Tribology Conference Tokyo 2015, 16-20 September, 2015 )

\begin{abstract}
To extend tool service life, several types of tapping tool coated with hard films have recently been developed. However, the detachment of films from tool surfaces and chip snarling on tools remain barriers to further increases in tap service life and tapping speed. In this study, a tapping tool coated with a composite film composed of nickel-phosphorus (Ni-P)/silicon carbide (SiC) particles was developed, and its machining performance was experimentally investigated. The composite film was coated on a spiral tap using electroless plating. Tapping tests demonstrated that the new tapping tool prevented chip snarling at five times the conventional cutting velocity. At such high velocities, chip snarling occurred on other taps, including one with a conventional steam-treated surface, one coated with a titanium carbo-nitride film and one coated with Ni-P plating taps. Furthermore, due to its high resistance to wear, the tool service life of the tapping tool coated with the composite film was approximately two times longer than that of the conventional steam-treated tapping tool. These results indicate that the tapping tool coated with the Ni-P/SiC composite film has the ability to increase processing efficiency and extend tool service life.
\end{abstract}

Keywords: chip snarling, electroless plating, friction, silicon carbide, tap

\section{Introduction}

Because of continuing advances in composite and metallic materials, improvements in tapping tools are required to increase processing efficiency, allow proper functioning at increased cutting velocities and extend the service life of taps. Tapping tools are generally classified into two types, i. e. roll tapping and cut tapping. One such cut tapping tool is the spiral tap, which has spiral flutes that allow chips to escape from the hole through the flute. However, at high cutting velocities, a conventional cut tapping tool causes the decreasing in the chip discharge ability, which results in chip snarling. The chip snarling causes the damage of workpiece material and chip packing, resulting in tool breakage [1-4]. Snarled chips must be removed manually, reducing the machining efficiency. Thus, chip snarling is a critical problem that must be overcome to satisfy the requirements mentioned above, i. e. increasing the cutting velocity as well as extending the tool service life.
Because of their high resistance to wear, oxidation and adhesion, hard coatings and lubricant coatings are an effective way to prolong the service life of tapping tools [5-8]. Jin et al. [5] reported that cubic boron nitride (cBN) film prevents adhesion of workpiece material (beta-type titanium alloy) to the coated tapping tool and improves the machining accuracy of the tapped thread. Reiter et al. [6] demonstrated that, by virtue of their excellent friction properties, lubricant coatings such as DLC and WC/C effectively reduce fluctuations in the cutting torque and prevent abrasive and adhesive wear of the tool. Henderer et al. [7] produced a tapping tool with a hard TiSiN base layer overlaid by a low-friction $\mathrm{CrCx} / \mathrm{a}-\mathrm{C}: \mathrm{H}$ top layer. Their hybrid coating demonstrated low friction and high wear resistance when tapping aluminum silicon. The combination of hard and lubricant coating layers allows chip flow with a low friction coefficient and reduces the cutting resistance [8]. However, the detachment of film from the tool surface remains a concern. Furthermore, the strong chip flow afforded by the hybrid coating will 
likely cause chip snarling on the tapping tool [9]. In metal cutting processes, chip breakage is an important indicator of chip snarling; the greater the chip breakage, the less snarling occurs [10]. The chip form (e. g., chip curl diameter) and chip flow direction (e. g., side curl angle) are closely related to the chip breakage properties, because chip breakage occurs after plastic strain is exerted on the chip free surface [11]. Previous studies for turning and drilling [12-14] have classified chip forms and experimentally and analytically investigated their formation processes. These studies indicated that the cutting conditions such as cutting velocity, uncut chip thickness, feed rate, tool geometry, etc., can control the chip geometry and affect chip discharge ability.

To our knowledge, chip snarling has not been investigated in the tapping process; thus, chip snarling continues to limit the efficiency of the tapping process. Given that chip breakage is expected to reduce chip snarling, we hypothesize that a new tapping tool will enable chip breakage during the tapping process.

Composite films composed of nickel-phosphorus (Ni-P)/abrasive particles, which is formed with electrodeposition [15-17] and electroless plating methods [18-20], has been applied to cutting tools and grinding wheels. Such composite films have not been applied to a cut tapping tool. The abrasive particles in the composite film should polish the chip surface so that damaged chips are easily broken and chip snarling is prevented. Therefore, we consider that such a composite film will prevent chip snarling on the tapping tool and increase tool service life, especially for high velocity cutting.

In this study, we aimed to test the above hypothesis. We developed a tapping tool coated with a composite film composed of Ni-P/abrasive particles and performed tapping tests to investigate whether the composite film prevents chip snarling and increases tool service life even at high cutting velocities.

\section{Experimental methods}

2.1. Tapping tool coated with a composite film composed of Ni-P/abrasive particles

Silicon carbide (SiC) particulates with a mean diameter of $1 \mu \mathrm{m}$ were used as the abrasive particulate for the composite film so that the particle is uniformly dispersed in the composite film on the tapping tool. The composite film was deposited on a high-speed steel (HSS) spiral tap by an electroless plating method. A schematic of the cross-section of the composite film is shown in Fig. 1. For comparison, another spiral tap was covered with a Ni-P plating film. These films were heat-treated at $300^{\circ} \mathrm{C}$; therefore, the hardness of the Ni-P layer was approximately doubled [20]: the hardness of Ni-P plating increased from $6.6 \mathrm{GPa}$ without hardening to $11.6 \mathrm{GPa}$ with hardening. Scanning electron microscope (SEM) images of the Ni-P plating film and the composite film are shown in

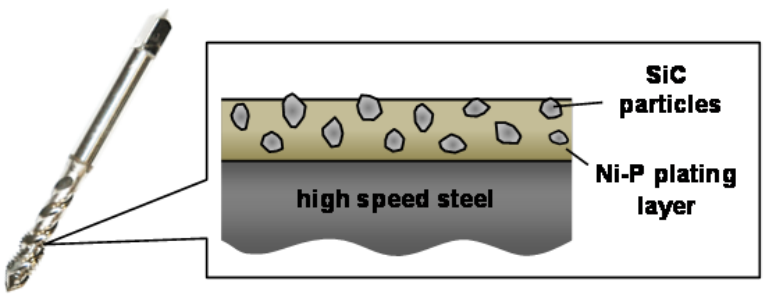

Fig. 1 Schematic of tap coated with the Ni-P/SiC composite film

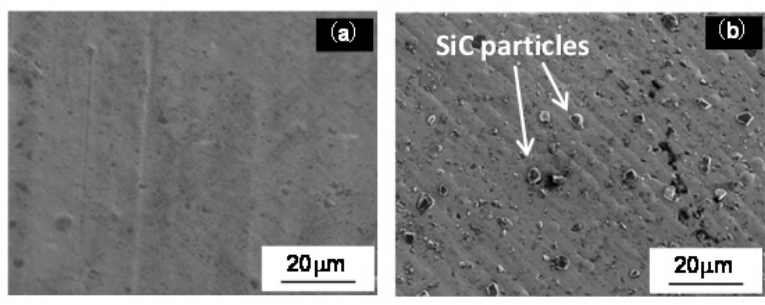

Fig. 2 SEM images of tap surface: (a) tap with the $\mathrm{Ni}-\mathrm{P}$ plating and (b) tap with the Ni-P/SiC composite film

Fig. 2. For the composite film, SiC particles appear on the surface of the electroless plated film (Fig. 2(b)).

\subsection{Tapping test}

To investigate the machining performance of the developed tapping tool, tapping tests were conducted using a machining center. Table 1 shows the tapping test conditions. The tested tapping tool was a spiral tap (HSS, M6 $\times 1$ ) having eight cutting edges with steamtreatment that makes the oxide of the iron layer $\left(\mathrm{Fe}_{3} \mathrm{O}_{4}\right)$ on the HSS tool surface [21] or coated with a titanium carbo-nitride (TiCN) coating film, a Ni-P plating film or the Ni-P/SiC composite film. The thickness of the composite film was $5 \mu \mathrm{m}$ and the others were about 1 $\mu \mathrm{m}$. The material of the workpiece was carbon steel (JIS $\mathrm{S} 45 \mathrm{C})$ in the form of rectangular blocks of $14.0 \times 310.0$ $\times 450.0 \mathrm{~mm}^{3}$. Tapping tests were performed on four tapping tools (one tool per treatment). A twist drill (HSS, diameter of $5.1 \mathrm{~mm}$ ) was used for machining the prepared hole.

Before the tapping tests, 750 prepared holes with a hole pitch of $10 \mathrm{~mm}$ were drilled using an emulsion cutting oil in a workpiece. The cutting velocity was $2200 \mathrm{rpm}$, and a feed rate of $396 \mathrm{~mm} / \mathrm{rev}$ was used for drilling the hole. The cutting velocity was $50 \mathrm{~m} / \mathrm{min}$, which is four times higher than the conventional cutting velocity $(10 \mathrm{~m} / \mathrm{min})$, and a synchronised feed control was used for tapping. The tapping test was conducted under lubrication with the emulsion cutting oil.

The cutting torque and thrust force in the tapping tests were measured using a dynamometer. Figure 3 is a representative plot of the temporal changes in the cutting torque during a single thread cutting. Points A, B, $\mathrm{C}$ and $\mathrm{D}$ in this figure indicate the times at which the first edge of the tapping tool contacts the workpiece, the eighth edge contacts the workpiece, the first edge of the tapping tool finishes cutting, and all edge finish cutting. 
Table 1 Experimental conditions

\begin{tabular}{|c|c|c|}
\hline \multirow{5}{*}{$\begin{array}{l}\text { Tool } \\
\text { (Spiral tap; HSS, M6 } \times 1 \text { ) }\end{array}$} & Surface treatment & Film thickness \\
\hline & $\begin{array}{l}\text { Steam-treatment } \\
\text { (conventional tap) }\end{array}$ & \multirow{3}{*}{$1 \mu \mathrm{m}$} \\
\hline & TiCN coating & \\
\hline & Ni-P plating & \\
\hline & Ni-P/SiC film & $5 \mu \mathrm{m}$ \\
\hline Workpiece material & \multicolumn{2}{|l|}{ Carbon steel (S45C) } \\
\hline Lubricant & \multicolumn{2}{|l|}{$\begin{array}{l}\text { Emulsion cutting oil } \\
\left(1.20 \mathrm{mPa} \cdot \mathrm{s} \text { at } 20^{\circ} \mathrm{C}\right)\end{array}$} \\
\hline Cutting velocity $v_{r}, \mathrm{~m} / \mathrm{min}$ & \multicolumn{2}{|l|}{50} \\
\hline
\end{tabular}

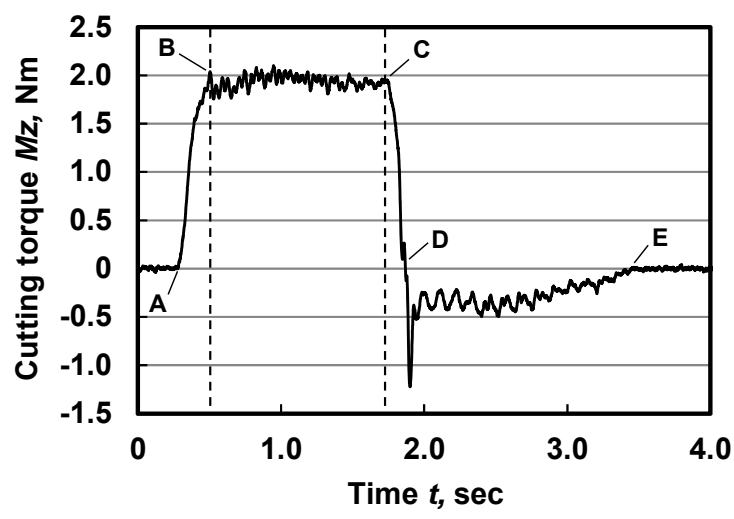

Fig. 3 Representative plot of the tapping torque throughout one cutting cycle

From A-C, tapping tool is driven in the forward direction; from D-E, it moves in the reverse direction. The mean cutting torque during the $\mathrm{B}-\mathrm{C}$ period was adopted in subsequent analysis. The tapping test was conducted on each tapping tool up to the tool service life, identified by either abnormal noise or breakage of the tool.

The tapping tools were observed after 25 thread holes to discover whether chips were snarled on the taps, and the chips were collected to investigate the chip snarling mechanism. When chips were snarled on the taps, the chips were removed every 100 holes.

\section{Results and discussion}

\subsection{Prevention of chip snarling}

Figure 4 shows the photographs of the tapping tools
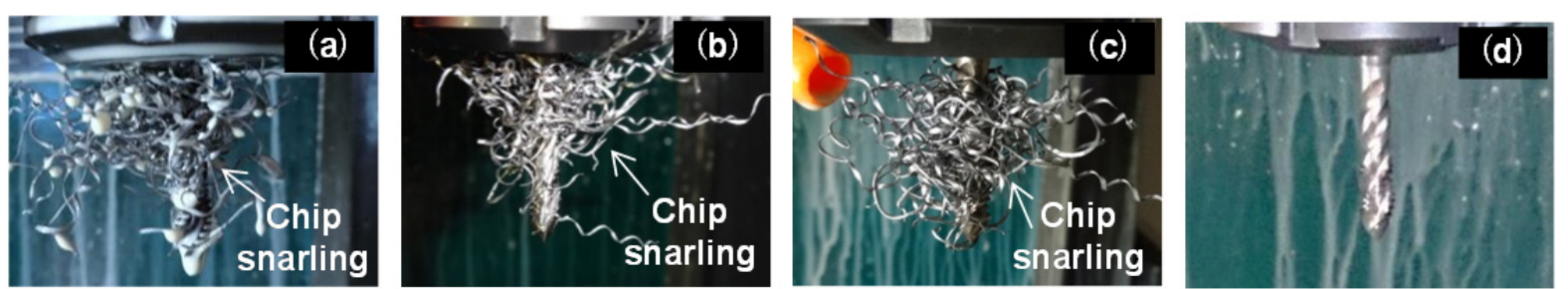

taken after 25 threaded holes were cut. As shown in the figure, chips were snarled on the taps with steam-treatment (Fig. 4(a)), coated with TiCN (Fig. 4(b)) and coated with the Ni-P plating film (Fig. 4(c)). In contrast, the tap covered with the $\mathrm{Ni}-\mathrm{P} / \mathrm{SiC}$ composite film (Fig. 4(d)) had no chip snarling on the tap surfaces. When carbon steel is processed, the conventional cutting velocity for tapping with a spiral tap is approximately $10 \mathrm{~m} / \mathrm{min}$. Therefore, the results demonstrate that the composite film enables continuous tapping without chip snarling at five times the conventional cutting velocity. This will result in increased processing efficiency for tapping. We confirmed the reproducibility of their results with additional tests. In addition, we measured the surface roughness of thread hole for steam-treatment and $\mathrm{Ni}-\mathrm{P} / \mathrm{SiC}$ film. The surface roughness of the thread hole for the developed tapping tool was 1.6 times higher than the roughness for steam treatment. The shape of thread holes cut by all of the tapping tools was tested by using the screw thread limit gauges, which is standardized in JIS B 3102. As a result, all thread holes satisfied this standard, which indicates that the quality, i. e. the dimension and precision, of the tapped thread hole was not deteriorated by our $\mathrm{Ni}-\mathrm{P} / \mathrm{SiC}$ tapping tool.

We hypothesized that the composite film encourages chip breakage during the tapping process; however, the lengths of the snarled chip and unsnarled chips collected after the tapping test were not significantly different (see Fig. 5). Therefore, a mechanism other than chip breakage prevents chip snarling on the tapping tool coated with Ni-P/SiC composite film. As shown in Fig. 5 , the snarled chip curls tend to have larger curvature

Fig. 4 Photographs of tapping tools: (a) steam-treatment, (b) TiCN coating, (c) Ni-P plating and (d) Ni-P/SiC film 

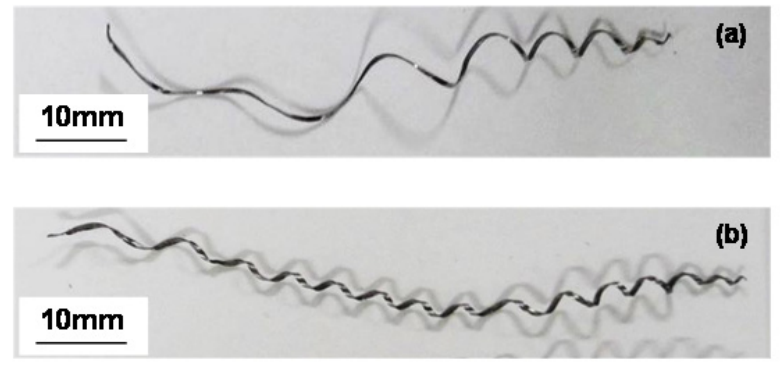

Fig. 5 Photographs of cutting chips: (a) snarled chip from tap with the TiCN coating and (b) unsnarled chip from tap with the $\mathrm{Ni}-\mathrm{P} / \mathrm{SiC}$ composite film
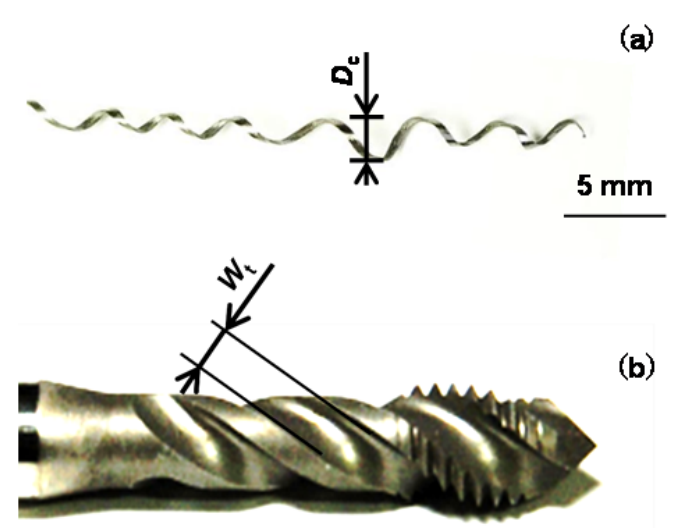

(b)

$10 \mathrm{~mm}$

Fig. 6 Geometric parameters of chip and tapping tool: (a) diameter of chip curl and (b) width of spiral flute

radius than the unsnarled chip curls, suggesting a role of the chip form. To investigate this idea, we measured the chip curl diameter of 30 chips collected after 25 thread holes. When chips were snarled on the tapping tool, we collected both discharged and snarled chips. We then newly introduced the dimensionless diameter of the chip curl $D_{\mathrm{d}}$, indicating the ratio of the chip curl diameter $D_{\mathrm{c}}$ (Fig. 6(a)) and the width of the flute of the tapping tool $W_{\mathrm{t}}$ (Fig. 6(b)). The dimensionless diameter is expressed as follows.

$$
D_{\mathrm{d}}=\frac{D_{\mathrm{c}}}{W_{\mathrm{t}}}
$$

Mean values of the dimensionless diameters of the chip curl $D_{\mathrm{d}}$ for each tapping tool are shown in Fig. 7. This figure is a box plot and the whiskers indicate the minimum and maximum values of the dimensionless diameter. As shown in Fig. 7, when chips were snarled on the tap, the maximum dimensionless diameters of the chip curls $D_{\mathrm{d}}$ were larger than 1.0. This indicates that the chip curl diameter is larger than the width of the tap flute $W_{\mathrm{t}}$. In contrast, when there were no snarled chips, the maximum dimensionless diameter of the chip curl $D_{\mathrm{d}}$ was less than 1.0. However, the $50 \% D_{\mathrm{d}}$ values of the tapping tools fabricated with steam-treatment and

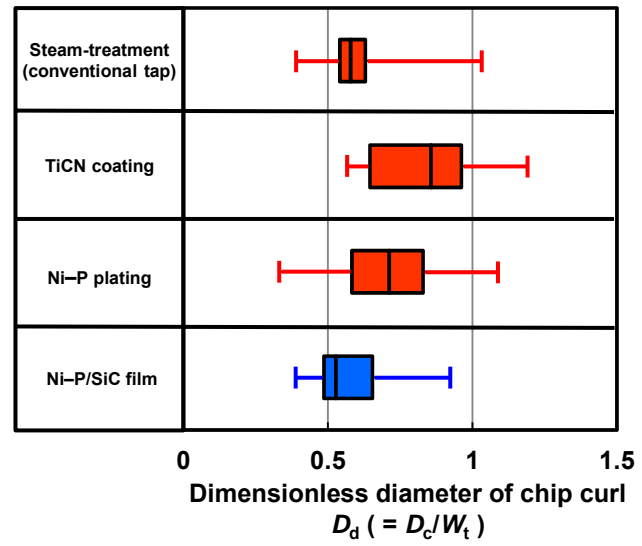

Fig. 7 Dimensionless diameter of chip curl
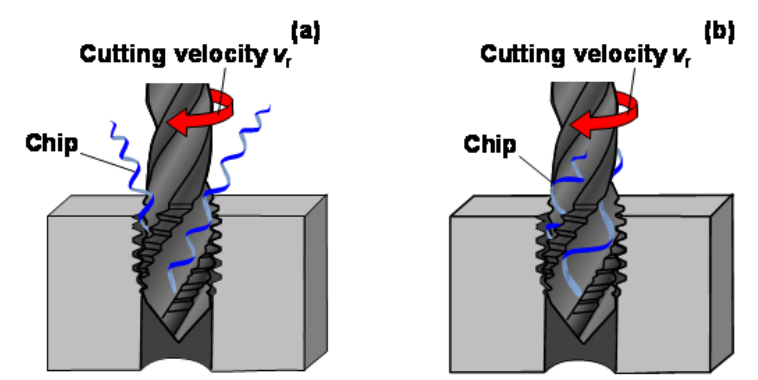

Fig. 8 Schematic images of tapping process: (a) no chip snarling $\left(D_{\mathrm{d}_{-} \max }<1\right)$ and (b) chip snarling $\left(D_{\mathrm{d} \max } \geq 1\right)$

Ni-P/SiC film were rather similar (see Fig. 7). Thus, snarling occurs when the chip curl diameter exceeds the tap flute width $W_{\mathrm{t}}$ (i. e., $D_{\mathrm{d}}>1.0$ ). Schematic images of the tapping process with no chip snarling and with chip snarling are shown in Fig. 8. In the case where the maximum dimensionless diameter of the chip curls $D_{\mathrm{d}}$ is less than 1.0, the chips are thrown out of the flute of the tapping tool by centrifugal force (Fig. 8(a)), resulting in no chip snarling. In contrast, in the case where the maximum dimensionless diameter of the chip curls $D_{\mathrm{d}}$ is larger than 1.0, the chips follow the spiral flute of the tapping tool without being thrown out and snarl on the tapping tool. Therefore, these results indicate that a decrease in the chip curl diameter should be effective to prevent chip snarling without breaking chips. At conventional cutting velocity $(10 \mathrm{~m} / \mathrm{min})$, we confirmed that the maximum dimensionless diameter of the chip curl $D_{\mathrm{d}}$ for steam-treatment and Ni-P film was less than 1.0 and these tapping tools had no chip snarling [22], which supports the results illustrated in Fig. 8.

Nakayama et al. [23] proposed two mechanisms for deforming chip curl in metal cutting processes. One is deformation caused by a chip breaker or built-up edge, and the other is deformation caused by secondary flow, i.e., the plastic flow in the part of the chip adjacent to the tool surface. In this study, the dimensions of the tapping tools were the same and a built-up edge existed in the rake face of all the tapping tools. Therefore, 
Table 2 Mean values of friction coefficients during friction test for each tested tap Material of pin specimen $(\phi=1 \mathrm{~mm})$ was carbon steel (JIS:S45C) for disk specimens with steam-treatment and covered with TiCN coating, the Ni-P plating film and the $\mathrm{Ni}-\mathrm{P} / \mathrm{SiC}$ composite film. Sliding velocity $v$ was $50 \mathrm{~m} / \mathrm{min}$, sliding distance $L$ was $4 \mathrm{~m}$ and normal load $W$ was $19.6 \mathrm{~N}$

\begin{tabular}{c|c|c|c|c}
\hline & $\begin{array}{c}\text { steam- } \\
\text { treatment }\end{array}$ & $\begin{array}{c}\text { TiCN } \\
\text { coating }\end{array}$ & $\begin{array}{c}\text { Ni-P } \\
\text { plating }\end{array}$ & $\begin{array}{c}\text { Ni-P/SiC } \\
\text { film }\end{array}$ \\
\hline $\begin{array}{c}\text { Friction } \\
\text { coefficient } \\
\mu_{\max }\end{array}$ & 0.14 & 0.12 & 0.11 & 0.19 \\
\hline
\end{tabular}

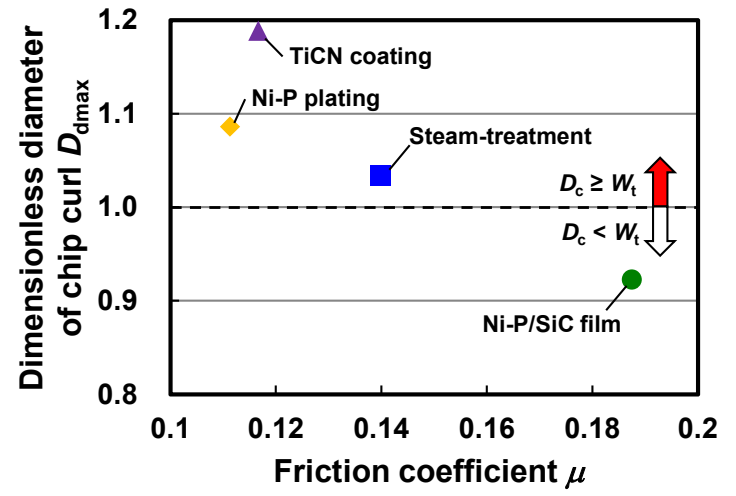

Fig. 9 Relationship between friction coefficient and (dimensionless) chip curl diameter

secondary flow was possibly the mechanism that caused the different chip curl diameters. It is well known that due to the secondary flow, i. e. plastic flow in the part of the chip adjacent to the tool surface, material flow in the chip is relatively slower at the adjacent to the tool rake face than at free face of the chip due to friction force at the rake face. This difference in the material flow velocity in the chip at tool rake face and free face causes the chip curl due to increasing the velocity in the material flow at the adjacent to the tool rake face when the chip is separated from the tool face. Thus, the diameter of the chip curl decreased as the thickness of the secondary flow layer increased. In addition, increased friction between the chip and tool surfaces also increased the thickness of the secondary flow, i. e. plastic flow layer,
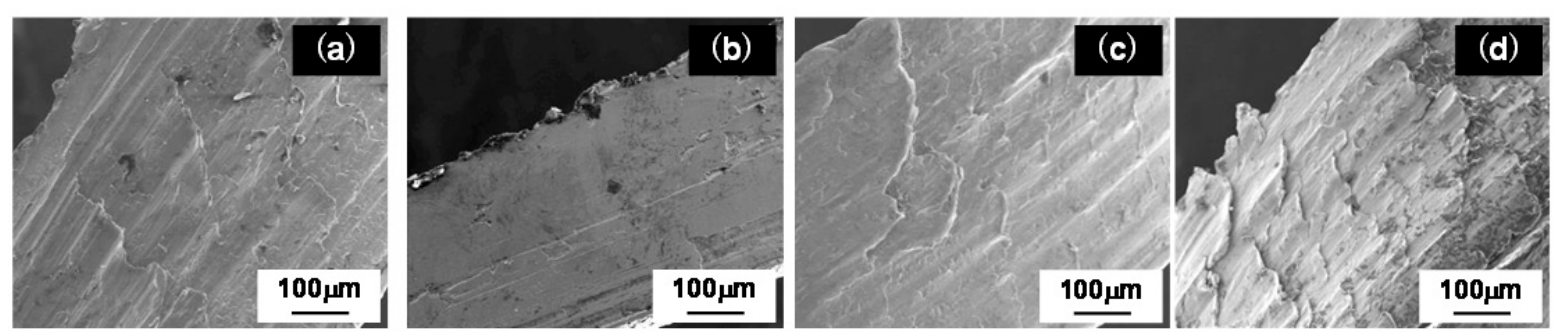

Fig. 10 SEM images of the chip surfaces yielded by: (a) steam-treated tap, (b) tap coated with TiCN film, (c) tap coated with Ni-P plating film, and (d) tap coated with $\mathrm{Ni}-\mathrm{P} / \mathrm{SiC}$ composite film resulting in decreased diameter of the chip curl. The friction coefficient for each tool surface treatment was measured using the pin-on-disk friction test. The mean steady-state friction coefficients obtained in the pin-on-disc experiments are presented in Table 2. The mean friction coefficient of $\mathrm{Ni}-\mathrm{P} / \mathrm{SiC}$ composite film contacted with carbon steel $(0.19)$ was 1.4 to 1.7 times higher those of other surface contacted with carbon steel ( 0.14 for steam-treatment, and 0.12 for TiCN coating; 0.11 for Ni-P plating). Figure 9 plots the maximum $D_{\mathrm{d}}$ as a function of the experimentally determined friction coefficients. Although the friction coefficient was not obtained at the tool-workpiece interface, it appears that a high friction coefficient at tool-workpiece interface will reduce the chip curl diameter and prevent chip snarling. Figure 10 shows SEM images of the chip surfaces sliding against the rake surfaces of the cutting edges of the tapping tools. We observe that the tool coated with TiCN film (Fig. 10(b)) yields the smoothest chips, whereas that coated with $\mathrm{Ni}-\mathrm{P} / \mathrm{SiC}$ composite film yields rougher chips than steam-treatment and $\mathrm{Ni}-\mathrm{P}$ platted tools. We surmise that the hard $\mathrm{SiC}$ particles in the composite film exerted a plowing effect, increasing the friction between the chip and rake surface of the tool cutting edge. These results suggest that the reduced chip curl diameter for the developed tapping tool was due to the increased secondary flow layer caused by its high friction.

\subsection{Tool service life extension}

Figure 11 shows the change in mean cutting torque 


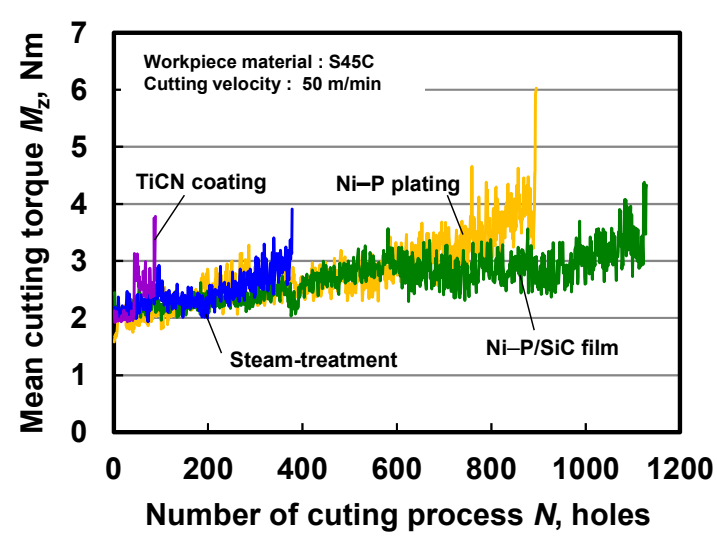

Fig. 11 Mean cutting torque with respect to the number of cutting processes for each tested tap

with respect to the number of cutting processes until each tapping tool reached the end of service life. For the tapping tools with steam-treatment, the Ni-P plating and the $\mathrm{Ni}-\mathrm{P} / \mathrm{SiC}$ composite film, the tapping test was terminated when abnormal noise occurred. The abnormal noise was determined as the sound pressure level measured during cutting exceeded $90 \mathrm{~dB}$. In contrast, the end of service life for the tap coated with TiCN was determined when the tap broke. The mean cutting torques for the tapping tools with steamtreatment, the Ni-P plating film and the Ni-P/SiC composite film gradually increased as the number of cutting processes increased. The tapping tool coated with the composite film had the longest service life among the tapping tools tested.

The number of cutting processes over tool service life is shown in Fig. 12. The tool service life of the tapping tool with the TiCN coating was the shortest among the four tools because of chip packing. The number of cutting processes of the tapping tool with the Ni-P plating was approximately 1.4 times larger than that of the tapping tool with the steam-treatment. In contrast, the number of cutting processes for the tapping tool covered with the composite film was approximately two times larger than that of the conventional steam-treated tapping tool.

SEM images of the rake faces of the tapping tools with steam-treatment and covered with the Ni-P plating film and the composite film are shown in Fig. 13. The

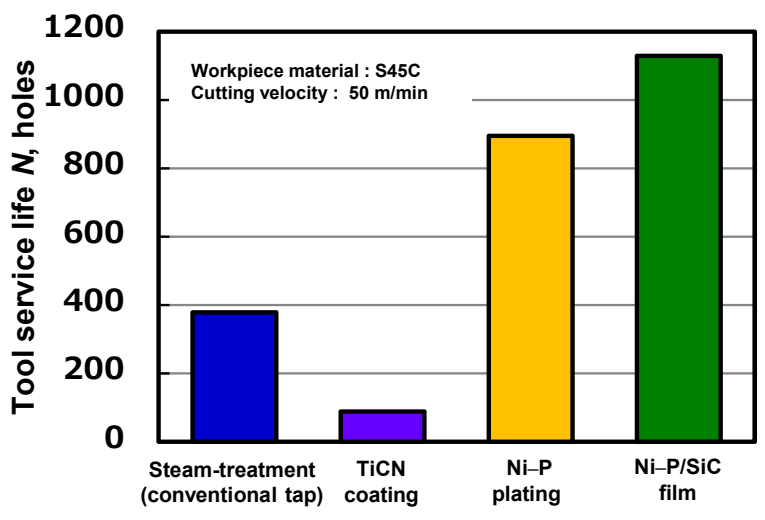

Fig. 12 Tool service lives for each tested tap

tapping tools with steam-treatment and covered with the Ni-P plating film had massive chipping on the cutting edge. In contrast, the edge of the developed tapping tool had little damage from chipping and wear.

In summary, the newly developed tapping tool coated with the composite film realized three times longer tool service life at five times higher cutting velocity compared with the conventional steam-treated tapping tool. The present study is the first attempt to use the $\mathrm{Ni}-\mathrm{P} / \mathrm{SiC}$ particles composite film in order to prevent the chip snarling on the tapping tool at high cutting velocity condition. The results clearly demonstrated the effectiveness of the composite film in preventing chip snarling as well as in increasing tool service life.

\section{Conclusions}

We present the first application of nickel-phosphorus (Ni-P)/abrasive particles to a cut tapping tool, and demonstrate that the composite film prevents chip snarling during tapping at high cutting speeds. A tapping tool covered with a composite film of the $\mathrm{Ni}-\mathrm{P} / \mathrm{SiC}$ particles was developed using an electroless plating method. Experimental investigation yielded the following results:

(1) The composite film on the developed tapping tool prevented chip snarling and enabled continuous tapping at five times the cutting velocity (50 $\mathrm{m} / \mathrm{min}$ ) used with a conventional tapping tool due to the reduced chip curl diameter.

(2) When the chip snarling was not occurred, the
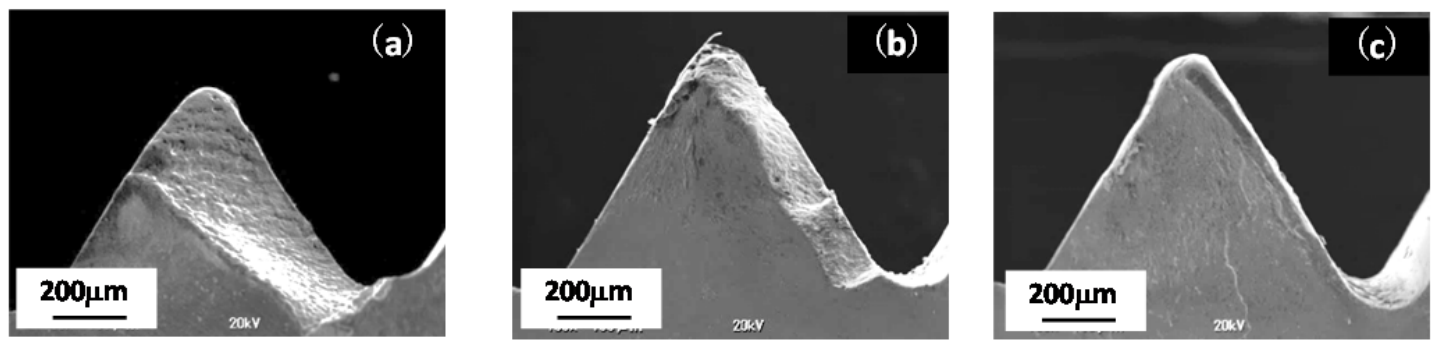

Fig. 13 SEM images of the rake face of tapping tools at the end of service life: (a) steam-treated tap and (b) tap coated with Ni-P plating film, and (c) tap coated with Ni-P/SiC composite film 
dimensionless diameter of the chip curl $D_{\mathrm{d}}$ was less than 1.0.

(3) At high cutting velocity $(50 \mathrm{~m} / \mathrm{min})$, the tapping tool coated with the composite film had an extended service life of up to approximately three times that of a conventional tapping tool.

\section{Acknowledgement}

This research was supported partly by the Center for Revitalization Promotion, Japan Science and Technology Agency.

\section{References}

[1] Araujo, A. C., Silveira, J. L., Jun, M. B. G., Kapoor, S. G. and DeVor, R., "A Model for Thread Milling Cutting Forces,” Int. J. Mach. Tool. Manu. 46, 2006, 2057-2065.

[2] Cao, T. and Sutherland, J. W., "Investigation of Thread Tapping Load Characteristics Through Mechanistic Modeling and Experimentation," Int. J. Mach. Tool. Manu., 42, 2002, 1527-1538.

[3] Yamauchi, M., Horiuchi, O., Murakami, Y., Sugano, H. and Shibutani, H., "Development of a Chip-Breaking Tool for Tapping (1st report): Prototype of the Tool and its Effectiveness," J. Jpn Soc. Precis. Eng., 70, 2004, 1565-1569 (in Japanese).

[4] Yamaoka, Y., Kakino, Y., Sato, T and Suzuki, Y., "High Speed, High Productive Tapping by Intelligent Machine Tools (2nd Report): Prevention of Tap Tool Breakage and Improvement of Productivity by Adaptive Control," J. Jpn. Soc. Precis. Eng., 67, 2001, 1338-1342 (in Japanese).

[5] Jin, M., Watanabe, S., Miyake, S. and Murakawa, M., "Trial Fabrication and Cutting Performance of c-BN-Coated Taps," Surf. Coat. Tech., 133-134, 2000, 443-447.

[6] Reiter, A. E., Brunner, B., Ante, M. and Rechberger, J., "Investigation of Several PVD Coatings for Blind Hole Tapping in Austenitic Stainless Steel," Surf. Coat. Tech., 200, 2006, 5532-5541.

[7] Henderer., W. and Xu, F., "Hybrid TiSiN, CrC/C PVD Coatings Applied to Cutting Tools," Surf. Coat. Tech., 215, 2013, 381-385.

[8] Derflinger, V., Brändle, H. and Zimmermann, H., "New Hard/Lubricant Coating for Dry Machining," Surf. Coat. Tech., 113, 1999, 286-292.

[9] Yan, J., Murakami, Y. and Davim, J. P., "Tool Design, Tool Wear and Tool Life," Machining dynamics, 2009, 117-149.

[10] Nakayama, K. and Arai, M., "Measurement of the Breakability of Chip," J. Jpn. Soc. Precis. Eng., 44, 1978, 1129-1135 (in Japanese).
[11] Kim, J. D. and Kweun, O. B., "A Chip-Breaking System for Mild Steel in Turning," Int. J. Mach. Tool. Manu., 37, 1997, 607-617.

[12] Buchkremer, S., Klocke, F. and Lung, D., "Analytical Study on the Relationship Between Chip Geometry and Equivalent Strain Distribution on the Free Surface of Chips in Metal Cutting," Int. J. Mech. Sci., 85, 2014, 88-103.

[13] Ke, F., Ni., J. and Stephenson, D. A., "Continuous Chip Formation in Drilling," Int. J. Mach. Tool. Manu., 45, 2005, 1652-1658.

[14] Hanasaki, S., Hosoi, R., Hosoi, T. and Nishimura, S., "Twist Drill Drillable Deep Hole Under Continuous High Feed Rate (Mechanism of Particular Type Chip Formation of 0-degree Rake Angle Twist Drill)," Trans. Jpn. Soc. Mech. Eng. C, 70, 2004, 1168-1173 (in Japanese).

[15] Ko, T. J. and Yoon, I. J., "Mill-Grinding with Electroplated Diamond Abrasives for Ceramic Cutting," Int. J. Precis. Eng. Man., 13, 2012, 5-10.

[16] Mizobuchi, A., Ogawa, H. and Sasaoka, T., "Grinding Force and Crack Size on Through-Hole Drilling of Glass Plate Used Electroplated Diamond Tool in Helical Drilling," J. Jpn. Soc. Abras. Technol., 54, 2010, 731-736 (in Japanese).

[17] Horne, D. F. and Loh, E., "Milling Optical Glass with Electroplated Diamond Tools," Opt. Acta: Int. J. Opt., 23, 1976, 709-722.

[18] Park, H. K., Onikura, H., Ohnishi. O. and Sharifuddin, A., "Development of Micro-Diamond Tools Through Electroless Composite Plating and Investigation into Micro-Machining Characteristics," Precis. Eng., 34, 2010, 376-386.

[19] Kita, Y., Ido, M. and Kuno, M., "Study on the Combined Grinding Machining (1st report): Production of Combined Machining Wheel by Electroless Plating," J. Jpn Soc. Precis. Eng,. 50, 1984, 585-590 (in Japanese).

[20] Balaraju, J. N., Sankara Narayanan, T. S. N. and Seshadri, S. K., "Electroless Ni-P Composite Coatings," J. Appl. Electrochem., 33, 2003, 807-816.

[21] Upadhyaya, G. S., "Power Metallurgy Technology," Cambridge Intl. Science Pub., Cambridge, 1998.

[22] Saito, Y., Yamaguchi, T., Shibata, K., Kadota, Y., Kubo, T., Watanabe, W., Sawabe, T. and Hokkirigawa, K., "Development of High-Functional Tap Using Electrodeposition of Cubic Boron Nitride Particles (Part2) -Machining Characteristics of cBN Particles Electrodeposited Tap-," Proc. JAST Tribology Conference, Fukuoka, Autumn 2013, in USB memory (in japanese).

[23] Nakayama, K., Uenoyama, M. and Tamura, K., "Chip Curl in Metal-Cutting Process," J. Jpn. Soc. Precis. Eng., 27, 1961, 681-688 (in Japanese). 


\section{Tribology Online}

\section{ERRATA}

Volume and issue: Vol.11, No.2 (2016)

Page: pp.81-87

Title: Development of a New Tapping Tool Covered with Nickel/Abrasive Particles Composite Film for Preventing Chip Snarling and Tool Service Life Extension

Author(s): Yasuyoshi Saito, Takeshi Yamaguchi, Kei Shibata, Yuki Kadota, Takeshi Kubo, Wataru Watanabe, and Kazuo Hokkirigawa

\begin{tabular}{|l|c|c|}
\hline & Appearing & Corrected \\
\hline $\begin{array}{l}\text { P.82 right column, 2. 2. Tapping test } \\
\text { second paragraph, line 4 }\end{array}$ & $396 \mathrm{~mm} / \mathrm{rev}$ & $396 \mathrm{~mm} / \mathrm{min}$ \\
\hline
\end{tabular}

Errata published; 31 January 2018 